\title{
The Effect of A Training Program in Improving First Classes Teachers Skills in Dealing with Special Needs Students in Regular Classroom in Amman
}

\author{
Heyam Musa Al-Taj ${ }^{1} \&$ Alia Mohammed Al-Oweidi ${ }^{2}$ \\ ${ }^{1}$ Amman Arab University, Jordan \\ ${ }^{2}$ The World Islamic Sciences and Education University, Jordan \\ Correspondence: Alia Mohammed Al-Oweidi, The World Islamic Sciences and Education University, Jordan. \\ E-mail: alia3bbadi@gmail.com
}

\author{
Received: November 5, $2016 \quad$ Accepted: December 14, $2016 \quad$ Online Published: April 29, 2017 \\ doi:10.5539/ies.v10n5p136 URL: https://doi.org/10.5539/ies.v10n5p136
}

\begin{abstract}
The purpose of this study is to investigate the effect of a training program in improving first classes female teachers' skills in dealing with special needs students in regular classroom among a sample of private schools female teachers in Amman. The study adopted the quasi-experimental approach based on two equivalent groups, as the sample consisted of (30) teachers distributed into two groups; an experimental group ( $\mathrm{n}=15)$, a control group $(n=15)$. To achieve the aim of the study, a scale to measure the level of teachers skills was developed consisting of (23) items administrated on the sample before and after the program which contained of (6) training sessions. The findings showed that the training program was effective in developing teachers' skills in dealing with special needs students, as the means of the experimental group developed on all sub-domains and the total degree of the scale. The findings showed that the post-performance of the control group was (2.11), meanwhile, it was for the experimental group (3.46), this indicates a difference in the performance of both groups. Moreover, the findings showed that there were no significant statistical differences in the extent of benefiting of the program according to years of experience and scientific qualifications variables. The study recommended the need to re-apply the program on other samples in other schools teaching special needs students.
\end{abstract}

Keywords: training program, special needs students, teachers in regular classroom

\section{Introduction}

The educational field has witnessed internationally great development and changes in all sectors and fields. It is known that education is the only way that helps the human to adapt to the problems facing him in the $21^{\text {st }}$ century and therefore education development issue is the educationalists and scholars' priority. And because education reform needs updating and change in the educational status and performance, it becomes a necessity to focus on the teacher which is the major element in education development process and consequently, education reform should be comprehensive taking into account all the issues related to the students (Donnely, 2010; Abdul-Jabbar, 2003).

In the previous years, special education followed an educational strategy to integrate the students with special needs with their peers in different fields in life including the education sector. Students with special needs enrolled into kindergartens, schools and universities and thus those students felt many changes in themselves and in their colleagues in the educational environment. Accordingly, the teacher need training that help them to deal with students with special needs in the ordinary classes (Al-Khateeb, 2007; Harakchiyska, 2010).

As the modern trends in the special education aim to integrate the students with special needs with other ordinary students, it has become a necessity to train the teacher on the cognitive and practical competences and so the teacher needs a set of skills and competences to ensure the success of such integration such as:

- $\quad$ Changing the content of the curricula to suit the students' situation.

- $\quad$ Focusing on teaching the basic skills to the students with special needs that are not included in the ordinary training program.

- The classroom environment's adaptation to suit the students with special needs. 
- $\quad$ Changing teaching strategies with students with special needs and focusing on the individual teaching.

- Highlighting the points of weakness that the students with special needs suffer from and strengthen the students' strong and positive points in addition ignoring shortage aspects which the students suffer from.

- $\quad$ Developing positive attitudes towards students with special needs.

- The necessity to corporate effectively with the school management to reduce the obstacles facing the students' progress in different academic, personal and social aspects.

- $\quad$ Establishing positive and permanent communication with the parents of the students with special needs in light of the educational programs.

- $\quad$ Providing linguistic and physical enforcement to the students that suit the student's academic, emotional and social progress.

- $\quad$ Enhancing the positive interaction between the students with special needs and the ordinary students.

- $\quad$ Effective coordination between the ordinary teacher and the teachers of special education whenever there is a necessity.

- Evaluate students' achievement using oral and written tests.

- Choose the effective methods that fit each disability and enhance the students' motivation (Chambers \& Forlin, 2010; Donnelly, 2010; Hartman, 2003; Brownell, Ross, Colon, \& McCallum, 2005).

In addition to the attention which is paid to the educational aspects of the student with special needs, the teacher in the ordinary class has important role in adjusting the student's behavior. It is known that modification the behavior is a prerequisite to learning so the teacher has to rearrange the classroom to reduce the appearance of the inappropriate behavior by reorder furniture and its tools in a way that allows the teacher to see all the students during their sitting and movement, in addition to the significance of employing time through increasing the time that the students' needs to finish his assignment inside the class, identifying the assignments that suit the students' needs and interest and redistributing the students to ensure having the students with negative behaviors with those who behave well to enhance the positive model. Furthermore, the teachers' personality helps in reducing the possibilities of the appearance of the negative behavior. The teachers' use of adjusting behavior strategies as positive enhancement, ignorance, negative enhancement, training on self-discipline and others are considered important in reducing the inappropriate behaviors as rebellion and disobedience, aggression, escape, self-harm (Edwards \& Protheroe,2003; Hu,2010).

Many studies study the important of teacher training in special Education such as Al-Ayid's (2003) study aimed to identify the problems facing the teachers at schools where the Resources Rooms are available and to explore the parents' perspective of the resources rooms. The sample of the study consisted of all the teachers of resources rooms. Results revealed that that there were problems related to the parents and the society concerning the parents' expectations about services provided in addition to lack of appropriate curricula to the students with special needs.

Aldweish (2006) conducted a study aimed to identify the status of the schools that have special education programs at Saudi Arabia in light of some international trends in the special education field. The sample of the study consisted of schools' principals, teachers and parents. The study's results showed that the current organizational structure of the schools that have special education programs is weak compared to their ordinary peers. Moreover, results showed the school's weak communication with similar educational institutions in the region. And thus, results showed the public education teachers and principals' acceptance of integrating the students with special needs in their schools but there were some obstacles facing these schools as the schools' weak experience in choosing the appropriate teaching method to succeed the integration, lack of the appropriate efficiency to work with students with special needs in additional lack of flexibility in making decisions.

Al-Khateeb (2007) conducted a study aimed to identify the level of the ordinary classes' teachers of learning difficulties and the effect of a training program based on the teachers' teaching beliefs. Results showed the teachers' level of knowledge of learning disabilities was moderate.

In Al-Sabah et al.'s (2008) study, they explored the difficulties facing integrating students with special needs in the basic public schools from the workers' perspective. The sample of the study consisted of 358 workers in the public schools (1st-10th grades). Results revealed lack of official evaluation used for the students with special needs and there is a positive attitude towards the integration of the students with disabilities in addition to lack of educational assessment tools to this category of students. Results also showed that students' individuals differences were not taken into consideration and the training was not enough for the teachers in addition to the 
limited number of the qualified people to deal with the students with special needs and lack of opportunities to host specialized and experts in the field of disabilities and special needs.

Al-Zoubi and Bani-Abdulrahman (2011) study aimed to construct a training program based on instructional competencies and to measure its effects in improving these competencies for special education resource room teachers in Jordan. The sample of the study consisted of 50 teachers. The participants were distributed into two equal groups, with 25 teachers in each group. The teachers in the experimental group were attached with the training program module; whereas the teachers in the control group were exposed to the conventional training program. The results revealed that there were statistically significant differences between the two groups' performance on the post-achievement test and the post-observation scale, favoring to the experimental group. The results of qualitative data analysis, that utilized interview methods showed significantly better performances of the experimental group teachers than of the control group in improving the personal and professional competencies.

The study of Shash (2012) aimed at revealing the most significant personal and professional competencies needed for the success of the teachers who work with the students with special needs. The sample of the study consisted of 289 male and female teachers of the private schools. The study concluded lack of statistical differences in the teachers' personal and professional competencies. But results also showed statistical significant differences between the teachers of hearing disability and the teachers of Visual disability in all of the personal, teaching competencies and technology employment in favor of the teachers of Visual disability.

Al-oweidi(2016) conducted a study aimed to identify the extent to which the first three classes teachers use not official tools to reveal the learning difficulties aspects in Amman. The sample of the study consisted of 100 male and female teachers of the first three grades. To achieve the study's goals, a scale to measure to which extent the teachers use assessment tools to explore learning difficulties aspects was built. Results showed that the extent of using these tools ranged from low to high and the most common tools that the teacher used were direct notice, error analysis while the least one used was case study and interview.

Problem of the study:

Although there is a growing interest in the students with special needs and the necessity of their integration in the ordinary classes, the effective steps on this issue are few. To achieve equality between education and the successful integration, some procedures should be taken into account to ensure the integration of the students with special needs in the ordinary classes, for example teachers should be trained how to deal with students with special needs in the ordinary classes. And since there are some private schools which hesitated to welcome the students with special needs because its teachers lack of the necessary skills in dealing with those students, this study aims to apply a training program on ordinary teachers and investigate its efficiency in raising these skills.

Questions of the study:

- What is the effect of the training program in raising first classes female teachers' skills in dealing with students with special needs in the Regular class?

- Does the effect of the training program in raising first classes female teachers' skills in dealing with students with special needs in the regular class vary according years of experience and scientific qualification variables?

Significance of the study:

- The interest in the subject of integrating the students with special needs in the regular classes and teachers' rehabilitation and preparation to deal with this category.

- Building two instruments; the first one is a tool to measure the teachers' skills level in dealing with the students with special needs in the regular classes and the second is a training program that helps the ordinary teacher to deal with the students with special needs in the ordinary class and thus to achieve better learning to this category.

Goals of the study:

- $\quad$ To identify the first classes female teachers' skills in dealing with students with special needs in the ordinary class

- To investigate the effect of a training program in raising first classes female teachers' skills in dealing with students with special needs in the ordinary class.

Limitations of the study: 
- Human\& spatial: the study is limited to a sample of first classes female teachers in one of the private school in Amman who teach students with special needs. The sample consisted of 30 teachers from different specializations except special education.

- $\quad$ Time: the program was applied during May 2015/2016.

- Methodology: the extent of the availability of the psychometric characteristics in the study's instruments in measuring the teachers' skills and the training program.

Procedural definitions:

- The skills: it is a set of professional and practical subjects that should be learnt to raise the teachers' skills level in dealing with the students with special needs in the ordinary class.

- The training program: it is a special program to the first classes female teachers includes training on the ways of dealing the students with special needs in the ordinary class and it has four dimensions: revealing, using appropriate teaching methods, behavior modification, communication with families) distributed into 6 training sessions.

- $\quad$ First classes teachers: the teachers who teach the first three grade students.

- Students with special needs: the students who are either talented or with disabilities and study in the ordinary schools.

\section{Method}

Methodology:

The quasi-experimental approach with two equivalent groups was used.

Population of the study:

The population of the study consisted of all the ordinary teachers who have students with special needs in their classes.

Sample of the study:

The sample of the study which was chosen purposefully consisted of 30 females teachers distributed into experimental group (30) and control one (30).

Instruments of the study:

First: scale of the first classes teachers' skills

The teachers built a scale to measure the skills which the first classes female teachers should have in dealing with the students with special needs. The scale consisted of 23 items distributed into four dimensions: revealing, using appropriate teaching methods, behavior modification, communication with families). Fifth -Lickert scale was adopted (very high, high, moderate, low, very low.

Scale validity:

To check the scale's validity, it was presented in its initial copy(35 items) to a set or arbitrators who are specialized in special education, counseling, and psychology at Arab Amman University and the World Islamic Science \& Education University. The arbitrators' comments were taken into account and the final copy consisted of 23 items distributed into four dimensions: revealing (1-6),using and employing teaching methods(7-13), behavior modification strategies(14-18) and communication with parents of the students with special needs(19-23).

Scale reliability:

To check the scale reliability, the internal consistency coefficient using Chrobch Alpha was calculated and its value which was (83.0) is considered acceptable for the purpose of the study.

The Scale correction:

Fourth-Lickert scale was adopted very high (4), high 3), moderate (2), low (1), very low (1). And to judge the teachers' skills level in dealing with the students with special needs, the skills were classified in to 3 levels high-moderate-low) according to the means of the respondents' performance on the scale. And the following criteria were adopted: low mean between (1-2), moderate (2-3) and high (3-4).

Second: training program

The researchers prepared a training program includes the necessary skills that the ordinary teacher should have 
to deal with the students with special needs in the ordinary class and thus helps in providing the best educational services and facilitates this category's learning in natural environment. this program aims to enable the ordinary teacher to have some skills that help him to provide the best educational services in a natural environment where ordinary students and the students with special needs learn together in the same class. the program includes four basic dimensions distributed into six sessions, each lasts 2 hours with $12 \mathrm{~m}$ as a break. The sessions includes PowerPoint presentation, discussions, purposeful dialogues, raising questions and doing some activities as it is illustrated below:

- $\quad 1^{\text {st }}$ session: it includes a meeting with the teachers to have friendly talk and introduce the program and its goals and components. The researchers illustrated to the teachers the procedures that should be followed to implement the program and its goals successfully. Later, there was a discussion about the first dimension which the procedures of revealing of the students with special needs in order to identify their educational needs.

- $\quad 2^{\text {nd }}$ session: introduce the teachers to the categories and classifications of the students with special needs.

- $\quad 3^{\text {rd }} \& 4^{\text {th }}$ sessions: introduce ways of using the appropriate educational teaching strategies to meet the students' needs and ways of modifying their behavior.

- $\quad 5^{\text {th }}$ session: introduces the use of different behavior modification strategies to get rid of undesirable behavior and acquire the desired ones.

- $\quad 6^{\text {th }}$ session: it introduces the important methods of communication and cooperation with the parents of the students with special needs to improve the students' performance.

Validity of the program:

The program was presented to 10 arbitrators specialized in special education, counseling, and psychology in the Jordanian universities. Their notes and suggestions were taken into account to improve the program with agreement $(80 \%)$ and some activities were modified.

Procedures

- After the instruments had been prepared, a specific school that has students with special needs who were taught by ordinary teachers was selected. The first instrument was applied on the school's teachers (30).

- There was an agreement with the school's principals to apply a training program after the school's final exams.

- The training program was applied on 15 teachers who showed their interest in attending this program.

- The skills scale was applied on all the teachers (15) to identify to which extent can the program raise the teachers' skills in dealing with the students with special needs in the ordinary classes.

- Data were collected and analyzed statistically.

Statistic treatment:

- To answer the first and second questions, the means and standard deviation of the two groups were calculated in the sub dimensions of the scale and the total degree.

- One Way ANCOVA was used to identify the differences between the means in the first question.

- The adjusted means were calculated to identify the difference value between the means of the groups' degrees in the post scale in the first question.

- $\quad$ The values of $\mathrm{T}$ test for the differences between the groups were calculated.

\section{Results and Discussion}

First question results \& discussion: To answer the first question: What is the effect of the training program in raising first classes female teachers' skills in dealing with students with special needs in the ordinary class?

The means and the standard deviation of the sub dimensions and total degrees were calculated as it is illustrated in Table 1. 
Table 1. Means \& standard deviation of the sub dimensions and the total degree

\begin{tabular}{|c|c|c|c|c|c|c|c|c|c|c|c|}
\hline \multirow[t]{2}{*}{ Group } & & \multicolumn{2}{|c|}{ Revealing \&identifying } & \multicolumn{2}{|c|}{ Teaching method } & \multicolumn{2}{|c|}{ Modifying behavior } & \multicolumn{2}{|c|}{ Communication with families } & \multicolumn{2}{|c|}{ Total scale } \\
\hline & & Pre & post & pre & Post & pre & post & pre & post & pre & post \\
\hline \multirow[t]{2}{*}{ Control } & M & 1.99 & 2.18 & 1.76 & 2.01 & 1.68 & 1.91 & 2.11 & 2.25 & 1.88 & 2.11 \\
\hline & Std & 0.47 & 0.62 & 0.45 & 0.57 & 0.38 & 0.54 & 0.39 & 0.44 & 0.38 & 0.53 \\
\hline \multirow[t]{2}{*}{ Experimental } & $\mathrm{M}$ & 3.08 & 3.39 & 3.04 & 3.43 & 3.17 & 3.47 & 3.33 & 3.46 & 3.18 & 3.46 \\
\hline & Std & 0.56 & 0.51 & 0.52 & 0.52 & 0.56 & 0.47 & 0.52 & 0.38 & 0.48 & 0.43 \\
\hline \multirow[t]{2}{*}{ Total } & M & 2.53 & 2.78 & 2.40 & 2.72 & 2.42 & 2.69 & 2.72 & 2.69 & 2.53 & 2.79 \\
\hline & Std & 0.75 & 0.83 & 0.81 & 0.90 & 0.89 & 0.93 & 0.77 & 0.93 & 0.79 & 0.84 \\
\hline
\end{tabular}

Table 1 showed that the experimental group's performance increased in all the sub dimensions and the total degree. Results which showed that the mean of the performance of the post total scale for the control was (2.11) and the experimental group (3.46) indicated a difference between the means of the experimental and control groups' performance. And to know whether this difference was statistically significant at $(a=0.05)$, One Way ANCOVA was used.

Table 2. ANCOVA results of the teachers' performance in the two groups in the scale of dealing with students with special needs

\begin{tabular}{cccccccc}
\hline Tool dimension & Source of variance & Sum of seq. & Fd & M of seq & F & Sig. & Program effect \\
\hline \multirow{4}{*}{ Revealing \&identifying } & Pre & 1.33 & 1 & 1.33 & 4.69 & 0.039 & 0.14 \\
& Training program & 1.94 & 1 & 1.94 & 6.84 & 0.014 & 0.203 \\
& Error & 7.66 & 27 & 0.28 & & & \\
& Total & 252.15 & 30 & & & & \\
& Pre & 0.22 & 1.00 & 0.22 & 0.72 & 0.40 & 0.03 \\
Teaching method & Training program & 3.70 & 1.00 & 3.70 & 12.36 & 0.00 & 0.31 \\
& Error & 8.08 & 27.00 & 0.30 & & & \\
& Total & 245.59 & 30.00 & & & & \\
Modifying behavior & Pre & 0.32 & 1.00 & 0.32 & 1.28 & 0.27 & 0.05 \\
& Training program & 3.13 & 1.00 & 3.13 & 12.45 & 0.00 & 0.32 \\
& Error & 6.79 & 27.00 & 0.25 & & & \\
& Total & 242.29 & 30.00 & & & & \\
& Pre & 0.49 & 1.00 & 0.49 & 3.05 & 0.09 & 0.10 \\
& Training program & 2.60 & 1.00 & 2.60 & 16.29 & 0.00 & 0.38 \\
& Error & 4.31 & 27.00 & 0.16 & & & \\
& Total & 276.80 & 30.00 & & & & \\
& Pre & 0.60 & 1.00 & 0.60 & 2.70 & 0.11 & 0.09 \\
& Training program & 1.81 & 1.00 & 1.81 & 8.12 & 0.01 & 0.23 \\
& Error & 6.04 & 27.00 & 0.22 & & & \\
& Total & 252.94 & 30.00 & & & &
\end{tabular}

The previous table showed statistical significant differences between the teachers' performance in both groups; control and experimental in the sub dimensions and the total degree of the scale. The values of the calculated (F) which ranged from 6.84-16.29 are considered statistical significant at $(\mathrm{a}=0.05)$ which indicates that there is a statistical significant difference in raising the teachers' level in dealing with students with special needs in the ordinary classes attributed to the training program variable.

To identify the degree of the effect of the educational program variable in raising the teachers' level in dealing with the students with special needs in the ordinary class, $\left(\eta^{2}\right)$ was calculated and its value in the total scale was $(0.23)$ and therefore we can say that $23 \%$ of the variance which raised the teachers' skills may due to the training program. And to identify the difference value between the groups in the post application, adjusted means were calculated as it is illustrated in Table 3 . 
Table 3. The adjusted means of the two groups' performance after eliminating the pre application effect

\begin{tabular}{lccc}
\hline Scale dimensions & Group & Adjusted mean & Std error \\
\hline \multirow{2}{*}{ Reaving \& identification } & Control & 2.41 & 0.17 \\
& Experimental & 3.16 & 0.17 \\
Teaching method & Control & 2.13 & 0.20 \\
& Experimental & 3.31 & 0.20 \\
\multirow{2}{*}{ Modifying behavior } & Control & 2.08 & 0.20 \\
& Experimental & 3.30 & 0.20 \\
Communication with families & Control & 2.43 & 0.14 \\
& Experimental & 3.44 & 0.14 \\
Total & Control & 2.33 & 0.18 \\
& Experimental & 3.24 & 0.18 \\
\hline
\end{tabular}

Results in Table 1 showed differences between the adjusted means of the two groups' degrees in the post application of the scale and its dimensions after eliminating the effect of the scale's pre application in favor of the experimental group. Consequently, it can be inferred that the training program succeeds in raising the teachers' level in dealing with the students with special needs in the ordinary class and this may due to the teachers' need and desire to have such training programs. It is worth mentioning the school where this study was applied is one of the schools that applies integration policy and welcomes the students with special needs although there are no specialized teachers in Special Education and so the teachers enthusiasm, efficiency and keenness to learn and improve their teaching skills was seen clearly.

Results of the second question:

To answer the second question: "Does the effect of the training program in raising the female teachers' skills level in dealing with the students with special needs in the ordinary class vary according to the years of experience and academic qualification variables?, means and stand deviations of the teachers' degrees in the pre and post application were calculated in addition to $\mathrm{T}$ test.

Table 4. Means, standard deviation and T test results of the teachers' performance in pre and post application according to the years of experience variable

\begin{tabular}{lccccc}
\hline Years of experience & N & M & Std & F & Sig. \\
\hline More than 5 & 6 & 3.63 & 0.38 & \multirow{2}{*}{0.00} & \multirow{2}{*}{0.992} \\
$6-11$ & 9 & 3.35 & 0.46 & & \\
\hline
\end{tabular}

It is noted from Table 4 that the means were close to each other and F value was $(0.00)$ which indicates lack of statistical significant differences.

Table 5. Means, standard deviation and T test results of the teachers' performance in pre and post application according to scientific qualification variable

\begin{tabular}{cccccc}
\hline Sig. & $\mathrm{F}$ & Std & $\mathrm{M}$ & $\mathrm{N}$ & \\
\hline \multirow{2}{*}{0.92} & \multirow{2}{*}{0.008} & 0.38 & 3.63 & 6 & Diploma \\
& & 0.46 & 3.35 & 9 & BA \\
\hline
\end{tabular}

Results in Table 5 showed that the means of the experimental group were close according to the scientific qualification variable. $\mathrm{F}$ value was $(0.008)$ which indicates lack of statistical significant differences and this result may due to the teachers' benefit of the training programs in the same degree regardless of their different years of experience and scientific qualifications. The teachers were exposed to new experience which is dealing with students with special needs in the ordinary class.

\section{Recommendations}

1) To generate the training program and apply it in other schools where students with special needs learn. 
2) The necessity to organize specialized training workshops to the schools that follow integration policy.

3) To reconsider the pre-service teachers' preparation by giving them more school books about students with special needs and ways of dealing with them inside the ordinaryclasses.

4) To encourage the schools in different sectors to welcome the students with special needs.

5) To work on the modification of the ordinary teachers' attitudes towards teaching the students with special needs in the ordinary class.

\section{References}

Abdul-Jabbar, A. A. (2003). The necessary training programs for special education teachers, Saudi Educational and Psychological sciences Association. King Saud University, 21, 139-179.

Alayid, W. (2003). Problems facing Resources rooms'teachers in the basic school (Unpublished thesis). Amman Arab University for Higher studies, Jordan.

Aldweish, A. (2006). A proposal to develop the management of schools that have special education programs in light of some international trends (Unpublished dissertation). Emam Mohammad bin Saud University, Saudi Arabia.

Al-Khateeb, J. (2007). Level of the ordinary grades teachers' knowledge of learning difficulties and the effect of a training program based of the teachers' beliefs. International conference of leaning difficulties, Riyadh, Saudi Arabia.

Al-Sbah, S., Khames, S., Sheikha, S., \& Awad, S. (2008). Difficulties facing retarded students' integration from the workers' perspective at basic public schools-A survey study. Palestinian Ministry of Education.

Al-weidi, A. (2016). The extent to which the first three grades teachers use the non-official instrument to revealing learning difficulties aspects in Amman city, conference of learning difficulties: Reality \& hopes. Journal of Childhood and Education, Bleida University, Algeria.

Al-Zoubi, S., \& Bani-Abdulrahman, M. (2011). The Effects of a Training Program in Improving Instructional Competencies for Special Education Teachers in Jordan. Educational Research, 2(3), 1021-1030.

Brownell, M., Ross, D., Colon, E., \& McCallum, C. (2005). Critical features of special education teacher preparation: A comparison with general teacher education. J. Spec. Educ., 38, 244-251. https://doi.org/10.1177/00224669050380040601

Chambers, D., \& Forlin, C. (2010). Initial teacher education and inclusion. In C. Forlin (Ed.), Teacher Education for Inclusion, Changing Paradigms and Innovative Approaches. London: Routledge.

Donnelly, V. (2010). Teacher Education for inclusion. International Literature Review European Agency for Development in Special Needs Education 2010.

Edwards, A., \& Protheroe, L. (2003). Learning to See in Classrooms. British Educational Research Journal, 29(2), 227-242. https://doi.org/10.1080/0141192032000060957

Harakchiyska, T. (2011). Training Teachers of Languages to Meet the Needs of Inclusive Classrooms KALBU STUDIJOS. 18 NR. STUDIES ABOUT LANGUAGES. NO. 18.

Hartman, J. M. (2003). Pre-service and classrooms teachers perceptions of best practices within a special education professional development school (Unpublished doctoral dissertation). Immaculata University.

Hu, B. (2010). Training Needs for Implementing Early Childhood Inclusion in China. International Journal of Early Childhood Special Education (INT-JECSE).

Shash, S. (2008). Personal and professional competencies needed for the success of the teachers of special education, the scientific conference at education college at Banha University, Discovering and caring of the talented: Reality \& hope (pp. 25-56).

\section{Copyrights}

Copyright for this article is retained by the author(s), with first publication rights granted to the journal.

This is an open-access article distributed under the terms and conditions of the Creative Commons Attribution license (http://creativecommons.org/licenses/by/4.0/). 